Article

\title{
Synergistic Adsorption and Flotation of New Mixed Cationic/Nonionic Collectors on Muscovite
}

\author{
Hao Jiang *, Wanying Ji, Qinhong Yang, Longhua Xu, Chen Zhao and Yuehua Hu \\ School of Minerals Processing and Bioengineering, Central South University, Changsha 410083, China; \\ 13548557025@163.com (W.J.); yangqh0520@163.com (Q.Y.); neulonghua@163.com (L.X.); \\ zhaochen_xy@163.com (C.Z.); hyh@csu.edu.cn (Y.H.) \\ * Correspondence: jianghao-1@126.com; Tel.: +86-731-8883-0545
}

Academic Editor: William Skinner

Received: 20 March 2017; Accepted: 8 May 2017; Published: 11 May 2017

\begin{abstract}
The mixed cationic collector cetyltrimethylammonium chloride (CTAC) and nonionic collector octanol (OCT) was found to exhibit a synergistic effect on the flotation and adsorption of muscovite. To understand the underlying synergistic mechanism, flotation, contact angle, surface tension, and adsorption measurements were carried out. The results obtained from flotation measurements indicated that the mixed CTAC/OCT exhibits a better collecting ability than CTAC or OCT. The recovery of muscovite with CTAC only rapidly decreased from $97.25 \%$ at $\mathrm{pH} 2.64$ to $75.26 \%$ at $\mathrm{pH} 5.82$, followed by a flat horizontal at a $\mathrm{pH}$ is higher than 6 . In contrast, a high recovery of greater than $85 \%$ muscovite was observed using mixed CTAC/OCT at $\alpha_{\mathrm{CTAC}}=0.67$ (the mole ratio of $\mathrm{CTAC}: \mathrm{OCT}=2: 1)$ over the investigated $\mathrm{pH}$ range. From the surface activity parameters $\left(\mathrm{CMC}, \gamma_{\mathrm{CMC}}\right.$, $\left.\Gamma_{\max }, A_{\min }\right)$ estimated from surface measurements and interaction parameters $\left(\beta^{m}, \beta^{\sigma}\right)$, in addition to the micellar and interfacial compositions $\left(x_{1}^{m}, x_{1}^{\sigma}\right)$ obtained from the theory of regular solutions, a synergistic effect is evident in the mixed micelle and at the water/air interface. Moreover, the mixed CTAC $/ \mathrm{OCT}$ at $\alpha_{\mathrm{CTAC}}=0.67$ exhibited the maximum synergistic interaction. The results obtained from surface tension measurements indicated that the mixed CTAC/OCT exhibits considerably higher surface activities compared to single CTAC or OCT. The contact angle results confirmed that the mixed CTAC/OCT is a better collector than the individual CTAC or OCT for the flotation of muscovite. According to the results obtained from adsorption experiments, compared with that of individual CTAC or OCT, the amounts of CTAC and OCT adsorbed on the muscovite surface are considerably increase in the mixed systems because of co-adsorption. Based on these results, the mixed CTAC/OCT exhibits a remarkable synergistic effect during the flotation and adsorption of muscovite.
\end{abstract}

Keywords: muscovite; mixed collectors; synergism; flotation; adsorption

\section{Introduction}

Muscovite has been commonly used in a wide range of industrial applications because of its distinctive properties, e.g., dielectric properties, heat resistance, and chemical resistance [1]. It is a typical two-layer-structured aluminosilicate, with a negatively charged tetrahedral layer owing to the isomorphic substitution of approximately $1 / 4 \mathrm{Si}^{4+}$ ions by $\mathrm{Al}^{3+}$ ions. These permanent charges are balanced by the interlayer $\mathrm{K}^{+}$ions, which serve as a bridge between the sheets [2,3]. The layer-to-layer cleavage of muscovite occurs easily, and the cleavage surface exposes $\mathrm{K}^{+}, \mathrm{Na}^{+}$, and $\left[\mathrm{SiO}_{4}\right]^{4-}$ ions, which can easily undergo hydrolysis and break away from the surface. Owing to the crystal structure of muscovite, the cleavage surface of muscovite is extremely hydrophilic and negatively charged. Hence, the cationic collectors are typically used for the flotation of muscovite. Unfortunately, several silicates accompanying muscovite are negatively charged under neutral or alkaline conditions and are 
doped into the flotation foam. In other words, it is apparently impossible to separate muscovite from these minerals using only cationic collectors [4].

In recent years, instead of pure components, mixed surfactants have been widely used as collectors for flotation because they typically exhibit better physical and chemical properties and synergistic effects compared to their corresponding single surfactants $[5,6]$. Several studies have reported the use of various mixed surfactant systems (nonionic/nonionic, ionic/ionic, and ionic/nonionic) for flotation. A collector mixture of dodecyl amine hydrochloride and sodium oleate exhibit enhanced activity for the flotation of muscovite [7]. The use of the mixed collectors of alkyl diamine/sulfonate has been used for the flotation of feldspar from quartz under acid conditions [8,9]. At an optimal molar ratio of 9:1 for sodium oleate and dodecyl ammonium chloride, high selectivity has been reported for the flotation of spodumene from feldspar $[10,11]$. Among numerous composite surfactant systems, the mixed cationic/nonionic surfactants are notable because they form spontaneous vesicles in the water phase and exert strong synergistic effects. Such synergistic effects can reduce the total amount of reagents used in industry, thereby reducing environmental pollution and economic costs [12-15].

The adsorption of surfactants at the solid-liquid interface is crucial in numerous application, such as emulsification, foaming control, detergents, surfactant-based separation, surface wetting modification, and flotation [16,17]. Although the adsorption mechanism of a single surfactant at the solid-liquid interface has been thoroughly investigated, few studies have reported the adsorption of mixed surfactant solutions. Furthermore, the use of mixed collectors for enhanced flotation and selectivity has only recently been recognized. Therefore, several studies focusing on mixed cationic/nonionic surfactant systems have recently been carried out [18-21]. In general, these mixed surfactant systems typically exhibit considerably higher surface activities than their individual components, leading to better wetting, solubilizing, and foaming behavior. In addition, the synergistic effects of mixed surfactants at the air/water interface and their co-adsorption on mineral surfaces have been reported [22-27]. Although comprehensive studies on mixed surfactants in aqueous systems have been conducted, several limitations exist. Hence, considerable efforts should be focused on understanding the underlying synergistic adsorption and flotation mechanism of mixed cationic/nonionic surfactants on minerals.

The objective of this work is to understand the synergistic flotation and adsorption of binary cationic/nonionic surfactant mixtures on muscovite. A binary surfactant mixture of cetyltrimethylammonium chloride (CTAC) and octanol (OCT) was used as collectors. The flotation performance of muscovite using the mixed CTAC/OCT was investigated by flotation measurements. In addition, surface tension, contact angle, and adsorption measurements were carried out to examine the adsorption characteristics and possible synergic effects at the gas-liquid or solid-liquid interfaces. Based on these measurements, the role of mixed cationic/nonionic collectors in the flotation and adsorption of muscovite is delineated.

\section{Materials and Methods}

\subsection{Materials and Reagents}

Muscovite samples used in this work were obtained from Hebei, China. These mineral samples were crushed to a size of less than $2 \mathrm{~mm}$ and added into a porcelain ball mill. Next, the fine particles were screened to obtain a size fraction of $-149+74 \mu \mathrm{m}$. Table 1 and Figure 1 show the compositional analysis of muscovite and its X-ray diffraction pattern, respectively. The results indicated that the muscovite sample was highly pure. The BET surface area of muscovite was measured as $2.431 \mathrm{~m}^{2} / \mathrm{g}$. The rock mineral samples provided by Guangzhou Richone Electronic Co., Ltd. (Guangzhou, China) were used for contact angle measurements. Analytically pure samples of CTAC and OCT purchased from Nanjing Robiot Co., Ltd. Analytical-grade hydrochloric acid $(\mathrm{HCl})$ and sodium hydroxide $(\mathrm{NaOH})$ were used as $\mathrm{pH}$ modifiers. Distilled water (resistivity $=18.2 \mathrm{M} \Omega \mathrm{cm}$ ) was obtained from an ultra-pure water machine. 
Table 1. Chemical composition of the mineral sample (mass fraction, \%).

\begin{tabular}{cccccccccc}
\hline Composition & $\mathrm{Al}_{2} \mathrm{O}_{3}$ & $\mathrm{SiO}_{2}$ & $\mathrm{Fe}_{2} \mathrm{O}_{3}$ & $\mathrm{TiO}_{2}$ & $\mathrm{CaO}$ & $\mathrm{MgO}$ & $\mathbf{K}_{2} \mathrm{O}$ & $\mathbf{N a}_{2} \mathrm{O}$ & $\mathbf{H}_{2} \mathbf{O}$ \\
\hline Muscovite & 28.96 & 46.55 & 5.30 & 0.74 & 0.19 & 0.97 & 10.53 & 3.24 & 3.23 \\
\hline
\end{tabular}

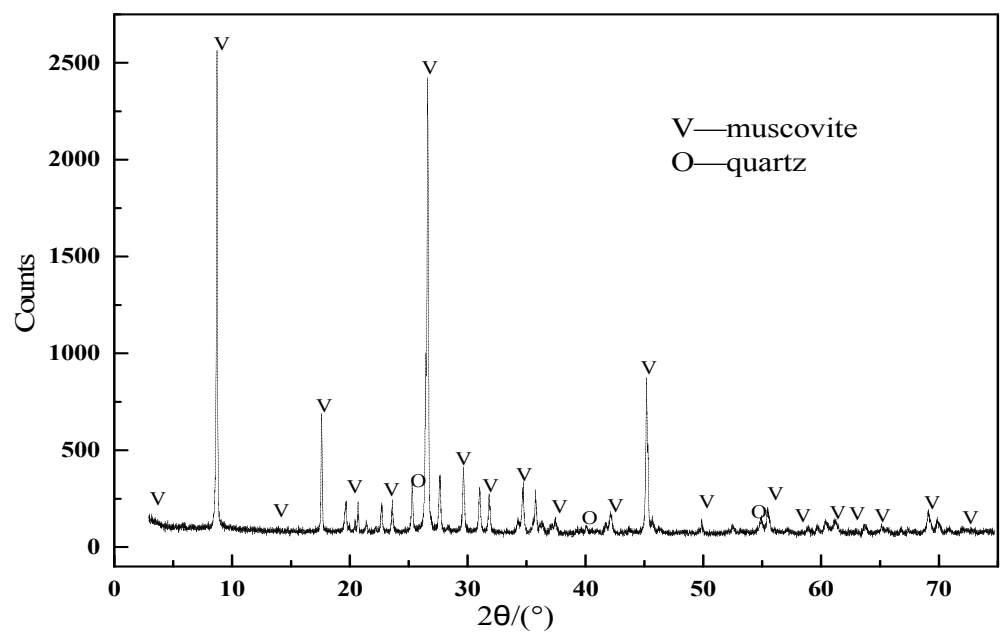

Figure 1. X-ray diffraction pattern of muscovite.

\subsection{Flotation Experiments}

Flotation tests with muscovite were carried out in a $40 \mathrm{~mL}$ flotation cell, and the speed of fixed impeller was $1600 \mathrm{r} / \mathrm{min}$. The air flow rate was $0.15 \mathrm{~m}^{3} / \mathrm{h}$. In each flotation test, $2 \mathrm{~g}$ of a muscovite sample and $35 \mathrm{~mL}$ of deionized water were used. Reagent grade $\mathrm{HCl}$ and $\mathrm{NaOH}$ were used to adjust the $\mathrm{pH}$. After adding the required reagents, the pulp was conditioned for $3 \mathrm{~min}$, followed by a flotation collection period of $3 \mathrm{~min}$. The froth products and tails were separately weighed after filtration and drying, the recovery rate was calculated. Each measurement was performed at least five times, and the average was reported as the final value.

\subsection{Surface Tension Measurements}

Surface tension was measured on a BZY-1 automatic tensiometer (Shanghai Hengping Instrument and Meter Factory, Shanghai, China) with a platinum plate at an environmental temperature of $25^{\circ} \mathrm{C}$. The tensiometer was calibrated using distilled water. The platinum plate was cleaned using deionized water and heated by an alcohol flame to ensure the complete removal of the organic matter and other impurities. Before the measurements, each sample was stabilized for 10 min until reaching equilibrium. Notably, each measurement was performed at least five times.

\subsection{Contact Angle Measurements}

The MiniLab ILMS (GBX, Rémy, France) instrument was used to measure the contact angles of muscovite. A sticky tape was used to freshly cleave the mineral sample surface, which permitted the observation of the perfect cleavage of muscovite along its basal planes. Reagent grade $\mathrm{HCl}$ and $\mathrm{NaOH}$ were used to adjust the solution $\mathrm{pH}$. First, the sample was conditioned at a certain concentration solution for $30 \mathrm{~min}$ at $25{ }^{\circ} \mathrm{C}$, followed by washing with washed with deionized water, drying under ultra-pure grade nitrogen, and performing the contact angle measurements. Notably, the sessile liquid drop technique was used to measure the contact angles of the samples. A single liquid drop (volume ca. $5 \mu \mathrm{L}$ ) was deposited onto the solid surface, and the static contact angle was measured. Each experiment was repeated at least five times at different locations of the dry solid muscovite sample and the final value of the contact angle was calculated as an average. 


\subsection{Adsorption Measurements}

A TOC-LCPH analyzer (Shimadzu, Kyoto, Japan) was used to measure the amount of adsorbed reagents on the mineral surface. First, mineral particles $(2.0 \mathrm{~g})$ were placed in a Plexiglas cell $(40 \mathrm{~mL})$ filled with $35 \mathrm{~mL}$ of deionized water. After adding a certain amount of collectors, the suspension was stirred for $3 \mathrm{~min}$ in the micro-flotation cell. Then, the conditioned pulp suspension obtained from the previous procedure was added to a $50 \mathrm{~mL}$ vial. After shaking the vials for $24 \mathrm{~h}$ at $25^{\circ} \mathrm{C}$, the supernatants were measured using the TOC-LCPH analyzer. The amount of the adsorbed collectors was calculated as follow:

$$
\Gamma=\frac{V\left(C_{0}-C\right)}{m A}
$$

Here, $C_{0}$ and $C$ are the initial and supernatant concentrations of quaternary ammonium salts, respectively. $V$ is the solution volume, $m$ is the sample mass, and $A$ is the particle specific surface area.

The total organic carbon (TOC) and total organic nitrogen (TON) in mixed CTAC/OCT were estimated using the TOC-LCPH analyzer. Nevertheless, to calculate the amount of the adsorbed OCT using a mixed CTAC/OCT system, the amount of the adsorbed CTAC must be calculated. Through the investigation, the concentrations of organic carbon $(\mathrm{OC})$ and organic nitrogen $(\mathrm{ON})$ in CTAC exhibited a linear relationship (Figure 2). So, according to Figure 2, the OC of CTAC can be obtained by the amount of ON and OC of OCT can be obtained by subtracting the OC of CTAC from the TOC of $\mathrm{CTAC} / \mathrm{OCT}$. The environmental temperature was maintained at $25^{\circ} \mathrm{C}$ and each measurement was performed at least three times.

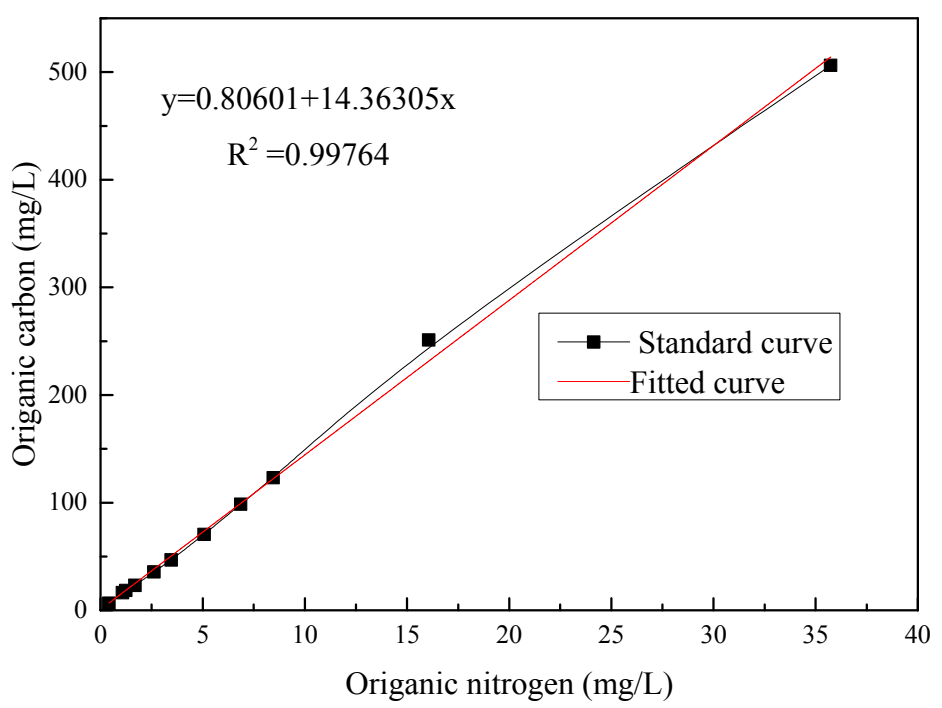

Figure 2. Standard curves of the linear relationship between organic carbon (OC) and organic nitrogen $(\mathrm{ON})$ in cetyltrimethylammonium chloride (CTAC).

\section{Results and Discussion}

\subsection{Flotation Results}

Figure 3a shows the effect of the collector concentration of CTAC, OCT, and the mixed CTAC/OCT surfactants on the flotation of muscovite at $\mathrm{pH}$ 7. The recovery of muscovite increased with increasing concentrations of CTAC and the mixed CTAC/OCT. However, the recovery of muscovite with OCT rarely changed with increasing concentration. In case of CTAC/OCT, the recoveries of muscovite rapidly increased at low collector concentrations, particularly at $\alpha_{\mathrm{CTAC}}=0.67$ (the mole ratio of CTAC:OCT $=2: 1$ ), which exceeded that of CTAC alone. For example, at a collector concentration of $8 \times 10^{-4} \mathrm{~mol} / \mathrm{L}$, the flotation recovery of muscovite in the presence of the mixed surfactant was approximately $73.25 \%$, whereas it was only approximately $45.9 \%$ for CTAC alone. The mixed 
CTAC/OCT collector is clearly beneficial for the flotation of muscovite. Therefore, a CTAC/OCT mole ratio of $2 / 1\left(\alpha_{\mathrm{CTAC}}=0.67\right)$ is selected for the subsequent studies, related to the significant improvement in the recovery of muscovite.

Figure $3 \mathrm{~b}$ shows the recovery of muscovite as a function of $\mathrm{pH}$ at a concentration of $1 \times 10^{-4} \mathrm{~mol} / \mathrm{L}$ for single or the mixed surfactants. The results indicate that the flotation of muscovite is almost not possible using OCT in the presence of OCT within the studied $\mathrm{pH}$ range. The recovery of muscovite using only CTAC rapidly decreased from $97.25 \%$ at $\mathrm{pH} 2.64$ to $75.26 \%$ at $\mathrm{pH} 5.82$, followed by a flat horizontal at a $\mathrm{pH}$ greater than 6 . However, the increase in the $\mathrm{pH}$ of the pulp exerted less impact on the recovery of muscovite using a mixed surfactant: the recovery of greater than $85 \%$ was maintained for muscovite using mixed surfactants in the investigated of $\mathrm{pH}$ range.
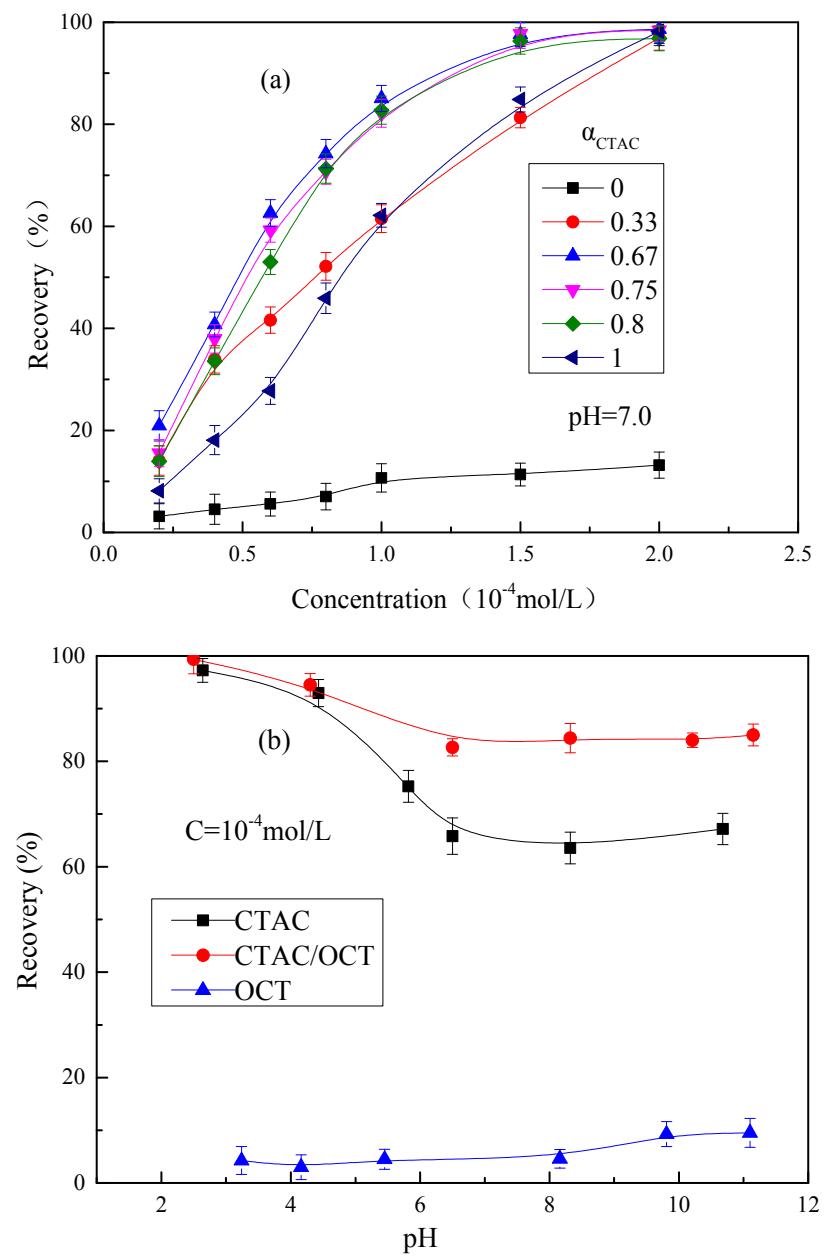

Figure 3. Flotation recoveries of muscovite with CTAC, OCT and mixed CTAC/OCT as a function of (a) concentration and (b) $\mathrm{pH}$.

\subsection{Surface Properties of Mixed Surfactants (CTAC/OCT)}

Figure 4 shows the surface tension $(\gamma)$ vs. log concentration $(C)$ plots at different molar ratios of mixed surfactants (CTAC/OCT) at $\mathrm{pH}$ 7. Table 2 lists the critical micelle concentration (CMC) values and surface tension at the $\mathrm{CMC}\left(\gamma_{\mathrm{CMC}}\right)$ for the corresponding surfactant mixture. For all mixed systems, the $\mathrm{CMC}$ and $\gamma_{\mathrm{CMC}}$ values were less than those obtained for the pure systems, indicating that mixed surfactants exhibit a stronger ability to reduce the surface tension of a solution compared to individual surfactants. Therefore, micro bubbles are more easily generated in mixed systems, which are more advantageous as they collide with particles and capture them. 
Moreover, the molar ratio of mixed CTAC/OCT clearly affected the value of CMC. The CMC values gradually decreased with increasing CTAC mole fraction and reached a minimum value $\alpha_{\mathrm{CTAC}}=0.67$, followed by the increase in the CMC values with increasing CTAC mole fraction. The decrease in the CMC values at the beginning is possibly related to the neutralization of hydrophilic groups by their electrostatic interactions. On the other hand, when $\alpha_{\text {СТAC }}$ was greater 0.67 , the individual surfactant exhibited self-interactions, thereby increasing the CMC.

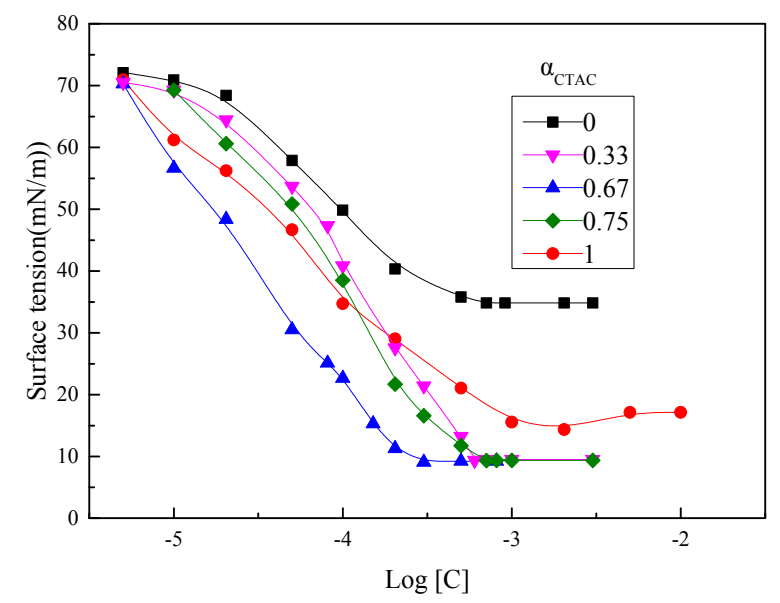

Figure 4. Surface tension vs. log concentration plots for CTAC, nonionic collector octanol (OCT), and mixed collectors CTAC/OCT at various molar ratios.

Furthermore, the minimum area per molecule $\left(A_{\min }\right)$ and the saturation adsorption value $\left(\Gamma_{\max }\right)$ are factors for confirming effective adsorption at the air/water interface [26]. The $\Gamma_{\max }$ and $A_{\min }$ values were calculated by the Gibbs adsorption Equations (2) and (3), respectively:

$$
\begin{gathered}
\Gamma_{\max }=-\frac{1}{2.303 n R T}\left(\frac{\partial \gamma}{\partial \log C}\right)_{T} \\
A_{\min }=\frac{1}{\Gamma N_{\mathrm{A}}}
\end{gathered}
$$

Here, $(\partial \gamma / \partial \log C)$ is the slope from the plot of surface tension vs. the logarithm of the total surfactant concentration at $25{ }^{\circ} \mathrm{C}, T$ is the absolute temperature $(298.15 \mathrm{~K}), R$ is the universal gas constant $\left(8.314 \mathrm{~J} \mathrm{~mol}^{-1} \mathrm{~K}^{-1}\right)$, and $N_{\mathrm{A}}$ is the Avogadro number $\left(6.023 \times 10^{23} \mathrm{~mol}^{-1}\right)$. The units of $\Gamma_{\max }$ is $\mu \mathrm{mol} / \mathrm{m}^{2}$, and $A_{\min }$ is in $\AA^{2}$. As has been reported previously [27], $n=1$ and $n=2$ for mixed CTAC/OCT and a single system, respectively.

Table 2 summarizes the $\Gamma_{\max }$ and $A_{\min }$ values for some of the mixtures investigated. In the investigated molar ratio range, the highest $\Gamma_{\max }$ and the lowest $A_{\min }$ values for the mixed collectors were observed at $\alpha_{\mathrm{CTAC}}=0.67$. Thus, the molecular arrangement in mixed CTAC/OCT is considerably denser compared to the individual surfactant, related to the fact that the strong electrostatic attractive interaction in all of the mixed systems dominates other weaker interactions.

Table 2. Surface properties of CTAC/OCT, $\alpha_{\mathrm{CTAC}}=0.0 .33,0.67,0.75$, and 1.00 in aqueous solutions

\begin{tabular}{|c|c|c|c|c|}
\hline$\alpha_{\text {CTAC }}$ & $\mathrm{CMC}\left(10^{-4} \mathrm{~mol} / \mathrm{L}\right)$ & $\gamma_{\mathrm{CMC}}$ & $\Gamma_{\max }$ & $A_{\text {min }}$ \\
\hline 0 & 5.49 & 34.81 & 1.78 & 93.27 \\
\hline 0.33 & 4.51 & 9.50 & 5.33 & 31.15 \\
\hline 0.67 & 2.18 & 9.24 & 6.36 & 26.11 \\
\hline 0.75 & 4.28 & 9.36 & 6.08 & 27.31 \\
\hline 1 & 10.08 & 15.54 & 2.21 & 75.13 \\
\hline
\end{tabular}
at $25^{\circ} \mathrm{C}$. 


\subsection{Synergism of the Mixed Collectors (CTAC/OCT)}

Based on the regular solution theory $[28,29]$, the nature and strength of the interaction between two components can be ascertained by calculating $\beta$ parameters (including $\beta^{m}$, the interaction parameter for mixed micelle formation in an aqueous solution, and $\beta^{\sigma}$, the interaction parameter for mixed adsorption film formation at the air/water interface). Notably, the $\beta$ value only reflects the molecular interactions between the head groups of two surfactants at the interface or in micelles. However, it does not consider the interaction between the hydrophobic alkyl chains of the surfactants [27]. In general, $\beta$ parameters are easily obtained from the surface tension or from CMC data.

According to the regular solution theory and Rubingh's theory of nonideal mixing, the mole fraction of CTAC in the mixed micelles $\left(x_{1}^{m}\right)$ and the micellar interaction parameter $\left(\beta^{m}\right)$ arecalculated using Equations (4) and (5), respectively:

$$
\begin{gathered}
\frac{\left(x_{1}^{m}\right)^{2} \ln \left(\alpha_{1} c_{12}^{m} / x_{1}^{m} c_{1}^{m}\right)}{\left(1-x_{1}^{m}\right)^{2} \ln \left[\left(1-\alpha_{1}\right) c_{12}^{m} /\left(1-x_{1}^{m}\right) c_{2}^{m}\right]}=1 \\
\beta^{m}=\frac{\ln \left(\alpha_{1} c_{12}^{m} / x_{1}^{m} c_{1}^{m}\right)}{\left(1-x_{1}^{m}\right)^{2}}
\end{gathered}
$$

Here, $x_{1}^{m}$ denotes the mixed micelles, which are related to $\alpha_{1}$ (CTAC mole fraction), $c_{1}^{m}, c_{2}^{m}$, and $c_{12}^{m}$ are $\mathrm{CMC}$ values for $\mathrm{CTAC}, \mathrm{OCT}$, and their mixture, respectively.

Moreover, using Rosen's approach, the mole fraction of CTAC in a mixed monolayer $\left(x_{1}^{\sigma}\right)$ and the interfacial interaction parameter $\left(\beta^{\sigma}\right)$ are calculated from Equations (6) and (7), respectively:

$$
\begin{gathered}
\frac{\left(x_{1}^{\sigma}\right)^{2} \ln \left(\alpha_{1} c_{12}^{s} / x_{1}^{\sigma} c_{1}^{s}\right)}{\left(1-x_{1}^{\sigma}\right)^{2} \ln \left[\left(1-\alpha_{1}\right) c_{12}^{s} /\left(1-x_{1}^{\sigma}\right) c_{2}^{s}\right]}=1 \\
\beta^{\sigma}=\frac{1 \ln \left(\alpha_{1} c_{12}^{s} / x_{1}^{\sigma} c_{1}^{s}\right)}{\left(1-x_{1}^{\sigma}\right)^{2}}
\end{gathered}
$$

Here, $c_{1}^{s}, c_{2}^{s}$, and $c_{12}^{s}$ are the molar concentrations of CTAC, OCT, and their mixture at a mole fraction of CTAC $\alpha_{1}$, required to produce a given surface tension reduction (corresponding to $\gamma=35 \mathrm{mN} / \mathrm{m}$ in this study).

As can be observed from Table $3, \beta^{m}$ and $\beta^{\sigma}$ values of all mixed systems were negative, indicating that the mixtures exhibit a stronger attractive interaction in the mixed micelles and at the solution/air interface compared to the two components before mixing. With increasing CTAC mole fraction, the $\beta^{m}$ and $\beta^{\sigma}$ values became more negative and reached the minimum at $\alpha_{\mathrm{CTAC}}=0.67$, indicating that the mixture at $\alpha_{\mathrm{CTAC}}=0.67$ exhibits a stronger attractive interaction compared to the other two mixed systems in the micelle. Notably, the $\beta^{\sigma}$ values were more negative than $\beta^{m}$, suggesting that the interactions at the solution/air interface are stronger compared to mixed micelles.

Table 3. Molecular interaction and synergistic parameters for mixed collectors CTAC/OCT at $\alpha_{\mathrm{CTAC}}=0.33,0.67$ and 0.75 , in $0.1 \mathrm{~mol} / \mathrm{L} \mathrm{NaCl}$ aqueous solutions.

\begin{tabular}{cccccc}
\hline$\alpha_{\text {CTAC }}$ & $x_{\mathbf{1}}^{m}$ & $\beta^{m}$ & $\left|\ln \left(c_{1}^{m} / c_{2}^{m}\right)\right|$ & $x_{1}^{\sigma}$ & $\beta^{\boldsymbol{\sigma}}$ \\
\hline 0.33 & 0.40 & -2.08 & 0.608 & 0.68 & -2.25 \\
0.67 & 0.51 & -6.66 & - & 0.71 & -10.07 \\
0.75 & 0.32 & -1.94 & - & 0.59 & -2.04 \\
\hline
\end{tabular}

Furthermore, synergism in the mixed micelle formation exists when the CMC of a mixture was less than that of the individual surfactants. Such a synergistic effect is observed s under two conditions, $\beta^{m}$ must be negative and $\left|\beta^{m}\right|$ must be greater than $\left|\ln \left(c_{1}^{m} / c_{2}^{m}\right)\right|$, respectively. All the condition were already satisfied (Table 2). The $\left|\beta^{m}\right|$ values were greater than those of $\left|\ln \left(c_{1}^{m} / c_{2}^{m}\right)\right|$ in all of the 
mixed collector systems, and all $\beta^{m}$ values were negative. This result further supported that mixed CTAC/OCT exerts a synergistic effect.

\subsection{Wettability of Muscovite with Mixed Collectors (CTAC/OCT)}

Contact angle measurements are crucial for investigating the wetting behavior of reagents on the muscovite surface. Before the sample is conditioned in the corresponding collector solution, we have measured the contact angle of muscovite with fresh cleavage, as muscovite surface is very hydrophilic, contact angle is only a few degrees. Figure 5 a shows the effect of concentration on the contact angles of muscovite. The contact angle of muscovite in the presence of CTAC/OCT was significantly greater than that in the presence of single CTAC at low surfactant concentration. On the other hand, at high surfactant concentration, the contact angles of muscovite using single CTAC and the mixed CTAC/OCT were maintained constant (approximately $86^{\circ}$ ). However, in the presence of single OCT, a relatively small contact angle was observed. Although the contact angle of the mica in the presence of OCT is larger than that in the water, OCT is a nonionic surfactant, the surface activity of OCT is relatively low, which cannot produce stable foam to capture muscovite particles. According to the above results, OCT itself cannot allow for good flotation unless CTAC is present, implying that CTAC plays a leading role in the overall synergistic adsorption and OCT only plays a supporting role.
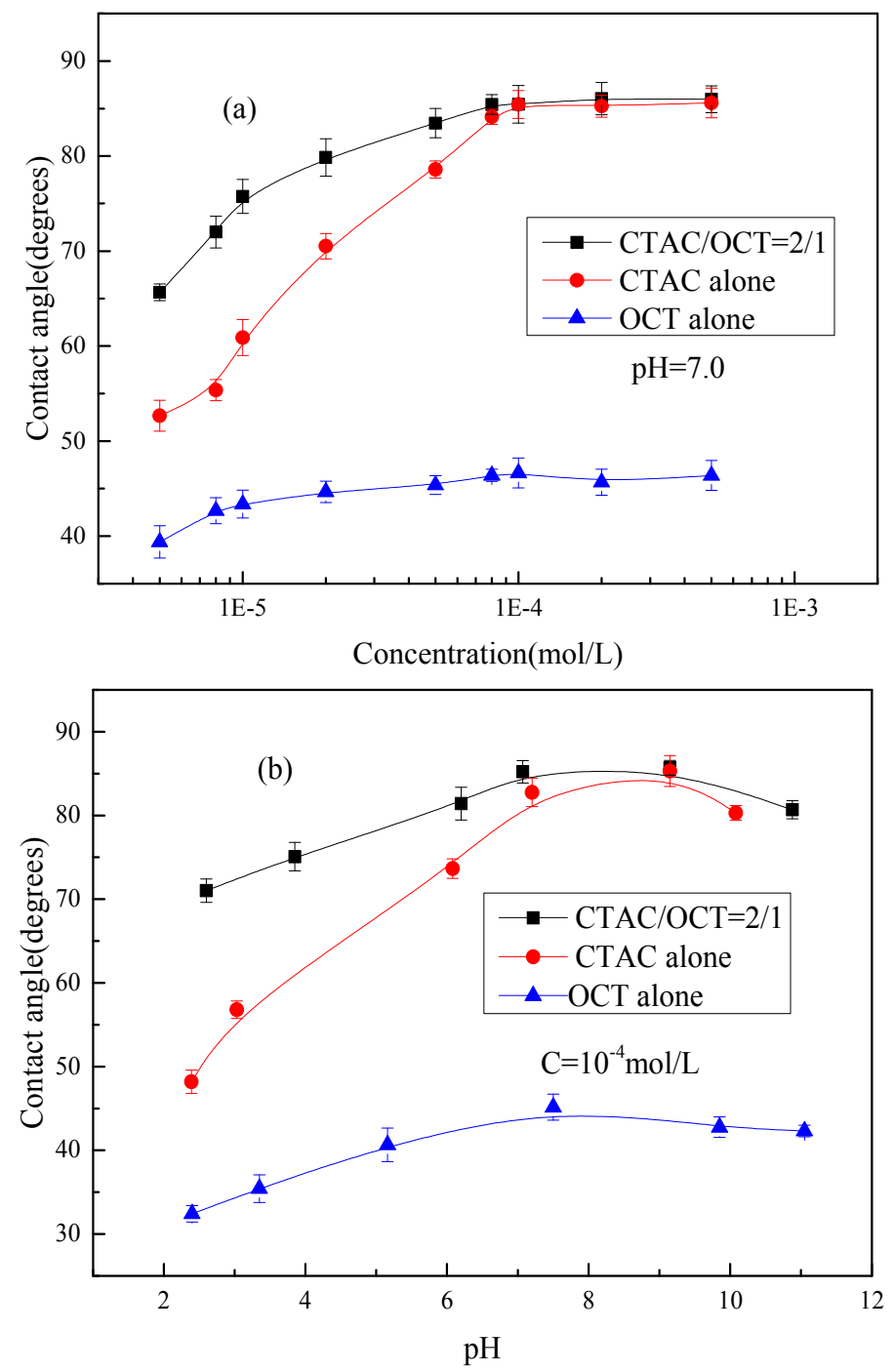

Figure 5. Contact angles of muscovite as a function of (a) concentration and (b) $\mathrm{pH}$. 
Figure $5 \mathrm{~b}$ shows the effect of $\mathrm{pH}$ on the contact angle of muscovite surface by using $10^{-4} \mathrm{~mol} / \mathrm{L}$ of corresponding reagents. At $\mathrm{pH}$ greater than 7 , the contact angle of muscovite gradually increased with increasing $\mathrm{pH}$ and was maintained at approximately $80^{\circ}$ using CTAC. In addition, the contact angle using OCT alone was still low. In contrast, with the use of mixed CTAC/OCT, pH marginally affected the contact angle of muscovite over the investigated $\mathrm{pH}$ range. Hence, the hydrophobicity of muscovite is gradually enhanced using the mixed CTAC/OCT. Notably, considerably different results between contact angle and flotation measurements were observed. This discrepancy results from the different particle size of the samples. A fine size fraction $(-149+74 \mu \mathrm{m})$ was used in flotation tests, while the plane was utilized for the contact angle tests. The contact angle test only reflects the properties of the cleaved muscovite surface (basal plane), but does not consider the edge surface, which also affects the flotation behavior.

\subsection{Adsorption Results}

The amount of the adsorbed collectors on the mineral surface directly affects the flotation behaviors of the minerals. Figure 6 shows the measured adsorption isotherms for the collectors adsorbed on muscovite as a function of the equilibrium concentration. The solution $\mathrm{pH}$ was controlled at approximately 7 . The changing trends of the curves clearly coincided with the first two regions of the four-region model. In the first stage, the electrostatic adsorption between surfactant ions and the negatively charged (001) basal planes is the dominant driving force for the considerable increase in the adsorbed amounts greatly, in addition to the cation exchange adsorption between the surfactant and the potassium ions released on the muscovite surface. In the second stage, the nonpolar carbon chains of collectors were highly intertwined with one another and formed a hydrophobic layer on the muscovite surfaces, affording a hydrophobic state [16].

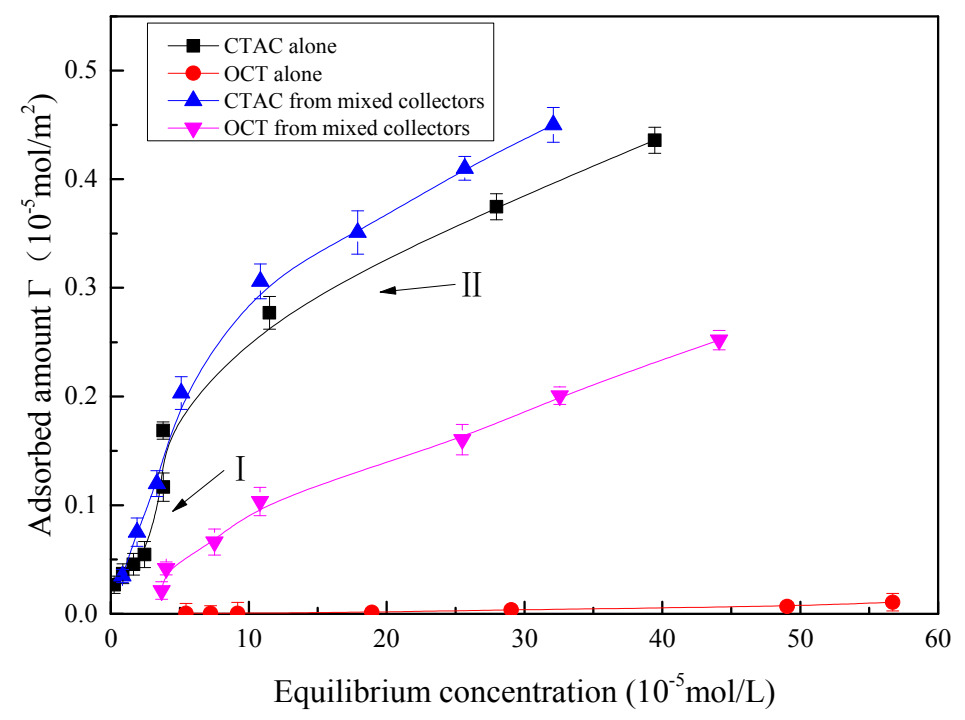

Figure 6. Adsorption isotherms of CTAC and OCT on muscovite from mixed CTAC/OCT solutions at a feed molar ratio of 2:1 CTAC/OCT $\left(\alpha_{\mathrm{CTAC}}=0.67\right)$ and $\mathrm{pH} 7.0$.

In addition, a small amount of OCT was adsorbed on the muscovite surface in the single OCT solution. However, in the presence of mixed CTAC/OCT, the adsorbed amount of OCT on the muscovite surface significantly increased. This increase can be explained by the co-adsorption OCT adsorbed between the molecules of CTAC through the hydrogen bonding and hydrophobic interactions, which can decrease the electrostatic repulsions between CTAC molecules and considerably enhance the adsorption of CTAC and OCT on the mineral surface. Because of the co-adsorption of CTAC and OCT on the muscovite surface in the mixed collectors, the amounts of adsorbed CTAC and OCT are distinctly increased. Such a synergistic effect between CTAC and OCT led to considerably stronger 
hydrophobicity on the muscovite surface and a better surface activity compared to single CTAC or OCT. Thus, the mixed CTAC/OCT can facilitate the flotation of muscovite.

\section{Conclusions}

In this study, a cationic collector cetyltrimethylammonium chloride (CTAC) and nonionic collector octanol (OCT) are found to exhibit a synergistic effect on the flotation and adsorption of muscovite. The following conclusions are therefore drawn: the mixed CTAC/OCT can facilitate the flotation of muscovite, indicating that that the mixed surfactants exhibit a stronger collecting ability than the individual CTAC or OCT, particularly at $\alpha_{\mathrm{CTAC}}=0.67$. The results obtained from surface tension tests and contact angle tests further confirm the synergistic effects of the mixed CTAC/OCT on the gas-liquid and solid-liquid interface. The maximum synergistic interaction is observed at $\alpha_{C T A C}=0.67$. According to the adsorption experiments, the adsorbed amounts of CTAC and OCT are distinctly enhanced due to the co-adsorption of CTAC and OCT on the muscovite surface in the presence of the mixture.

Acknowledgments: The authors would like to thank the National Natural Science Foundation of China (Grant Nos. 51674207, 50974134 and 51304162) for their support.

Author Contributions: Hao Jiang, conceived of and designed the experiments. Wangying Ji, Qinghong Yang, and $\mathrm{Chen}$ Zhao performed the experiments and analyzed the data. Longhua $\mathrm{Xu}$, Yuehua $\mathrm{Hu}$, and Hao Jiang contributed reagents and materials. Wangying Ji and Qinghong Yang wrote the paper.

Conflicts of Interest: The authors declare no conflict of interest.

\section{References}

1. Xu, L.; Wu, H.; Dong, F.; Wang, L.; Wang, Z.; Xiao, J. Flotation and adsorption of mixed cationic/anionic collectors on muscovite mica. Miner. Eng. 2013, 41, 41-45. [CrossRef]

2. Yan, L.; Masliyah, J.H.; Xu, Z. Interaction of divalent cations with basal planes and edge surfaces of phyllosilicate minerals: Muscovite and talc. J. Colloid Interface Sci. 2013, 404, 183-191. [CrossRef] [PubMed]

3. Xu, L.; Hu, Y.; Dong, F.; Gao, Z.; Wu, H.; Wang, Z. Anisotropic adsorption of oleate on diaspore and kaolinite crystals: Implications for their flotation separation. Appl. Surf. Sci. 2014, 321, 331-338. [CrossRef]

4. Nakazawa, H.; Ogasawara, S.; Sato, H. Separation of sericite from quartz by amine flotation. Nippon Kogyo Kaishi 1988, 104, 803-807. [CrossRef]

5. Rao, K.H.; Forssberg, K.S.E. Mixed collector systems in flotation. Int. J. Miner. Process. 1997, 51, 67-79.

6. Von Rybinski, W.; Schwuger, M.J. Adsorption of Surfactant Mixtures in Froth Flotation. Langmuir 1986, 2, 639-643. [CrossRef]

7. Xu, L.; Hu, Y.; Tian, J.; Wu, H.; Wang, L.; Yang, Y.; Wang, Z. Synergistic effect of mixed cationic/anionic collectors on flotation and adsorption of muscovite. Colloids Surf. A 2016, 492, 181-189. [CrossRef]

8. Poorkani, M.; Banisi, S. Industrial use of nitrogen in flotation of molybdenite at the Sarcheshmeh copper complex. Miner. Eng. 2005, 18, 735-738. [CrossRef]

9. Ejtemaei, M.; Gharabaghi, M.; Irannajad, M. A review of zinc oxide mineral beneficiation using flotation method. Adv. Colloid Interface Sci. 2014, 206, 68-78. [CrossRef] [PubMed]

10. Tian, J.; Xu, L.; Deng, W.; Jiang, H.; Gao, Z.; Hu, Y. Adsorption mechanism of new mixed anionic/cationic collectors in a spodumene-feldspar flotation system. Chem. Eng. Sci. 2017, 164, 99-107. [CrossRef]

11. Xu, L.; Hu, Y.; Tian, J.; Wu, H.; Yang, Y.; Zeng, X.; Wang, Z.; Wang, J. Selective flotation separation of spodumene from feldspar using new mixed anionic/cationic collectors. Miner. Eng. 2016, 89, 84-92. [CrossRef]

12. Desai, T.R.; Dixit, S.G. Interaction and Viscous Properties of Aqueous Solutions of Mixed Cationic and Nonionic Surfactants. J. Colloid Interface Sci. 1996, 177, 471-477. [CrossRef]

13. Penfold, J.; Staples, E.J.; Tucker, I.; Thompson, L.J. Adsorption of Mixed Cationic and Nonionic Surfactants at the Hydrophilic Silicon Surface from Aqueous Solution:Studied by Specular Neutron Reflection. Langmuir 1997, 13, 6638-6643. [CrossRef]

14. Dixit, S.G.; Vanjara, A.K.; Nagarkar, J.; Nikoorazm, M.; Desai, T. Co-adsorption of quaternary ammonium compounds-Nonionic surfactants on soild-liquid interface. Colloids Surf. A 2002, 205, 39-46. [CrossRef] 
15. Desai, T.R.; Dixit, S.G. Coadsorption of Cationic-NonionicSurfactant Mixtures on Polytetra Fluoroethylene (PTFE) Surfave. J. Colloid Interface Sci. 1996, 179, 544-551. [CrossRef]

16. Somasundaran, P.; Krishnakumar, S. Adsorption of surfactants and polymers at the solid-liquid interface. Colloids Surf. A 1997, 123, 491-513. [CrossRef]

17. Blanco, E.; Rodriguez-Abreu, C.; Schulz, P.; Ruso, J.M. Effect of alkyl chain asymmetry on catanionic mixtures of hydrogenated and fluorinated surfactants. J. Colloid Interface Sci. 2010, 341, 261-266. [CrossRef] [PubMed]

18. Wang, L.; Hu, Y.; Liu, J.; Sun, Y.; Sun, W. Flotation and adsorption of muscovite using mixed cationic-nonionic surfactants as collector. Powder Technol. 2015, 276, 26-33. [CrossRef]

19. Fang, X.; Zhao, S.; Mao, S.; Yu, J.; Du, Y. Mixed micelles of cationic-nonionic surfactants: NMR self-diffusion studies of Triton X-100 and cetyltrimethylammonium bromide in aqueous solution. Colloid Polym. Sci. 2003, 281, 455-460. [CrossRef]

20. Jones, T.; Rubingh, D.N. Mechanism of Detergency in Systems Containing Cationic and Nonionic Surfactants. Ind. Eng. Chem. Prod. Res. Dev. 1982, 21, 176-182.

21. Wang, L.; Hu, Y.; Sun, W.; Sun, Y. Molecular dynamics simulation study of the interaction of mixed cationic/anionic surfactants with muscovite. Appl. Surf. Sci. 2015, 327, 364-370. [CrossRef]

22. Vora, S.; George, A.; Desai, H.; Bahadur, P. Mixed Micelles of Some Anionic-Anionic, Cationic-Cationic, and Ionic-Nonionic Surfactants in Aqueous Media. J. Surfactants Deterg. 1999, 2, 213-221. [CrossRef]

23. Hao, L.S.; Deng, Y.T.; Zhou, L.S.; Ye, H.; Nan, Y.Q.; Hu, P. Mixed micellization and the dissociated Margules model for cationic/anionic surfactant systems. J. Phys. Chem. B 2012, 116, 5213-5225. [CrossRef] [PubMed]

24. Rojas, Y.V.; Phan, C.M.; Lou, X. Dynamic surface tension studies on poly(N-vinylcaprolactam/ $\mathrm{N}$-vinylpyrrolidone/ $\mathrm{N}, \mathrm{N}$-dimethylaminoethyl methacrylate) at the air-liquid interface. Colloids Surf. A 2010, 355, 99-103. [CrossRef]

25. Maiti, K.; Bhattacharya, S.C.; Moulik, S.P.; Panda, A.K. Physicochemistry of the binary interacting mixtures of cetylpyridinium chloride (CPC) and sodium dodecylsulfate (SDS) with special reference to the catanionic ion-pair (coacervate) behavior. Colloids Surf. A 2010, 355, 88-98. [CrossRef]

26. Zhao, S.; Zhu, H.; Li, X.; Hu, Z.; Cao, D. Interaction of novel anionic gemini surfactants with cetyltrimethylammonium bromide. J. Colloid Interface Sci. 2010, 350, 480-485. [CrossRef] [PubMed]

27. Wang, R.; Li, Y.; Li, Y. Interaction Between Cationic and Anionic Surfactants: Detergency and Foaming Properties of Mixed Systems. J. Surfactants Deterg. 2014, 17, 881-888. [CrossRef]

28. Rosen, M.J.; Zhou, Q. Molecular Interactions of Surfactants in Mixed Monolayers at the Air/Aqueous Solution Interface and in Mixed Micelles in Aqueous Media:The Regular Solution Approach. Langmuir 2003, $19,4555-4562$.

29. Khan, I.A.; Mohammad, R.; Alam, M.S.; Kabir-ud-Din. Surface Properties and Mixed Micellization of Cationic Gemini Surfactants with Ethyleneamines. J. Chem. Eng. Data 2010, 55, 370-380. [CrossRef] 